\title{
Geologi dan Identifikasi Cebakan Bijih di Daerah Batubesi, Belitung Timur
}

\author{
Geology and Ore Deposits Identification In Batubesi Area, Belitung Timur
}

\author{
Ngadenin*, Frederikus Dian Indrastomo, Adhika Junara Karunianto, Ersina Rakhma \\ Pusat Teknologi Bahan Galian Nuklir - BATAN, \\ J1. Lebak Bulus Raya No.09, Ps. Jumat, Jakarta, 12440 \\ *E-mail: ngadenin@batan.go.id
}

Naskah diterima: 17 April 2017, direvisi: 10 Mei 2017, disetujui: 31 Mei 2017

\begin{abstract}
ABSTRAK
Wilayah Batubesi di Belitung Timur berada di zona bagian timur dari granit jalur timah Asia Tenggara sehingga diduga merupakan daerah yang sangat potensial bagi terbentuknya cebakan bijih seperti besi dan timah bersama dengan monasit dan mineral asesoris lainnya. Penelitian ini bertujuan untuk mengetahui tataan geologi dan mengidentifikasi keterdapatan cebakan bijih dan mineral ikutan radioaktif di daerah Batubesi. Metodologi dalam penelitian ini adalah pemetaan geologi, pengukuran kadar uranium dan thorium, analisis petrografi, mineragrafi, dan butir. Daerah penelitian tersusun atas satuan granit dan metabatupasir. Granit diidentifikasi sebagai granit biotit dan granit hornblenda. Struktur geologi yang berkembang adalah sesar sinistral berarah barat daya - timur laut dan sesar dekstral berarah tenggara - barat laut. Cebakan bijih yang terbentuk di merupakan cebakan bijih besi primer tipe skarn iron tin polymetallic dengan magnetit sebagai mineral utama dan monasit serta zirkon sebagai mineral ikutan radioaktif . Mineral ikutan lainya adalah hematit, ilmenit, kasiterit, dan rutil.
\end{abstract}

Kata kunci: geologi, radioaktif, Batubesi, kasiterit, bijih besi, monasit.

\begin{abstract}
The Batubesi area in Belitung Timur is located in the eastern part of the Southeast Asian granites tin belt zone, so that it expected as a potential area for the occurence of ore deposit such as iron and cassiterite associate with monazite and other accessories minerals. The study aimed to understand the geological setting and to determine the occurrence of primary ore deposit and its radioactive accessories minerals. The methodologies in this research are geological mapping, uranium and thorium grade measurement, petrography, mineragraphy and grain counting analysis. The area composed by granite and metasandstone units. Types of granites are biotite and hornblende granites. The geological structures founded in this area are SW-NE sinistral and NW-SE dextral faults. Ore deposit in the area is primary iron ore deposits of skarn iron tin polymetallic type where magnetite is the main mineral while monazite and zircon are radioactive accessories minerals. The other accessories minerals are hematite, ilmenite, cassiterite, and rutile.
\end{abstract}

Keywords: geology, radioactive, Batubesi, cassiterite, iron ore, monazite.

\section{PENDAHULUAN}

Granit jalur timah Asia Tenggara menyebar dari utara ke selatan mulai dari Myanmar-Thailand-Malaysia-SingapuraIndonesia. Secara umum provinsi granitoid jalur timah Asia Tenggara di Indonesia terbagi menjadi dua provinsi, yaitu provinsi granitoid jalur utama dan provinsi granitoid jalur timur (Gambar 1). Cebakan bijih pada jalur utama adalah cebakan tipe greisens, dengan mineral terdiri atas kasiterit dan wolframit sedangkan cebakan bijih pada jalur timur adalah cebakan tipe skarn yang dengan mineral terdiri atas magnetit, kasiterit, dan 
mineral-mineral logam dasar sulfida. Mineral radioaktif monasit dan zirkon merupakan mineral ikutan pada kedua tipe cebakan bijih tersebut sedangkan mineral ikutan lainnya adalah ilmenit, hematit, dan rutil [1].

Daerah Batubesi, Kecamatan Damar, Kabupaten Belitung Timur diperkirakan merupakan bagian dari zona granitoid jalur timur sehingga diharapkan di daerah Batubesi akan didapatkan cebakan bijih primer tipe skarn dengan mineral utama adalah magnetit dan mineral ikutan radioaktifnya adalah monasit dan zirkon serta mineral ikutan lainnya adalah kasiterit. Secara geologi regional, daerah Batubesi merupakan daerah kontak antara batuan malihan Formasi Kelapakampit yang berumur Permo Karbon dengan diorit kuarsa Batubesi yang berumur Kapur.

Penelitian ini bertujuan untuk mengetahui tataan geologi dan mengidentifikasi cebakan bijih primer yang terbentuk beserta mineral ikutan radioaktif sebagai dampak yang ditimbulkan dari kondisi geologi di daerah Batubesi. Lokasi penelitian terletak di bagian timur laut pulau Belitung, secara administratif termasuk ke dalam wilayah Desa Mengkubang, Kecamatan Damar, Kabupaten Belitung Timur, Provinsi Bangka Belitung (Gambar 2).

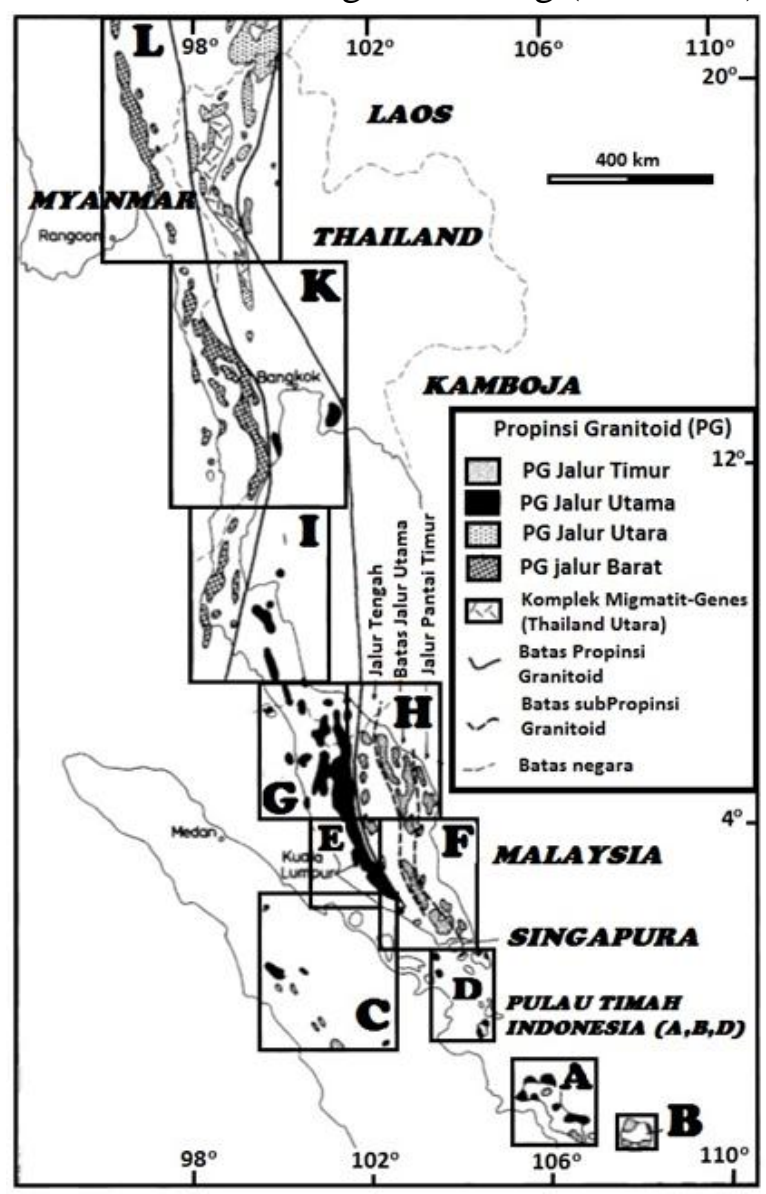

Gambar 1. Penyebaran granit jalur timah Asia Tenggara[1].

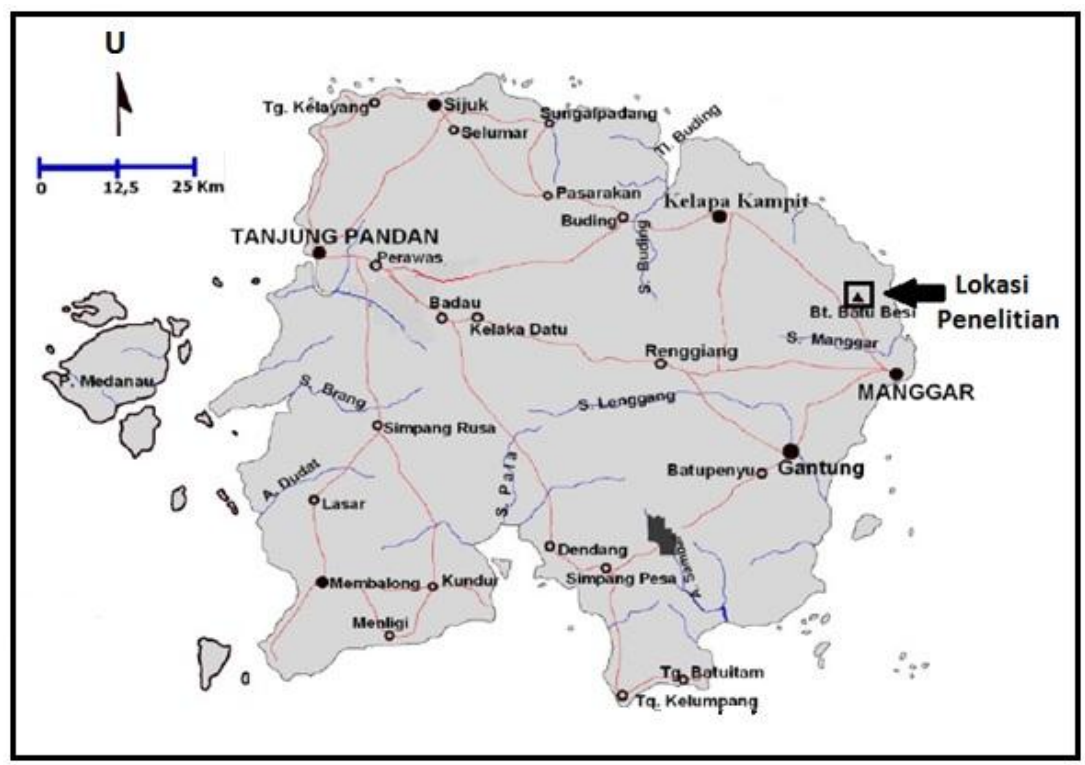

Gambar 2. Peta lokasi penelitian, secara administratif termasuk ke dalam Kabupaten Belitung Timur. 


\section{TATA KERJA}

Peralatan dan bahan yang digunakan dalam penelitian ini terdiri dari:

a. Peralatan pemetaan geologi terdiri dari Global Positioning System (GPS), kompas geologi, palu geologi, kaca pembesar, dan kamera sedangkan bahan yang digunakan adalah peta dasar, yaitu peta geologi dan peta topografi lembar Belitung, Sumatera skala 1:250.000.

b. Peralatan pengukuran kadar uranium dan thorium, yaitu spektrometer sinar gamma tipe RS-125.

c. Peralatan analisis petrografi, yaitu mikroskop polarisasi menggunakan bahan sayatan tipis batuan.

d. Peralatan analisis mineragrafi, yaitu mikroskop pantul menggunakan bahan sayatan poles bijih.

e. Peralatan untuk analisis butir konsentrat mineral berat, yaitu mikroskop binokuler dengan bahan konsentrat mineral berat hasil pendulangan.

Metode penelitian yang digunakan adalah sebagai berikut:

a. Pemetaan geologi berskala 1:10.000 pada daerah seluas $12,5 \mathrm{~km}^{2}$ dengan cara pengamatan singkapan pada lintasan yang telah ditentukan (Gambar $3)$.

b. Pengambilan sampel batuan pada lokasi yang dianggap mewakili untuk analisis petrografi (Gambar 3). Analisis petrografi bertujuan untuk mengetahui jenis batuan dan komposisi mineralnya. Sampel batuan segar selanjutnya dibuat sayatan tipis dan diamati dengan mikroskop polarisasi sinar tembus.

c. Pengukuran kadar uranium dan thorium dilakukan menggunakan alat spektrometer sinar gamma RS-125 dengan cara membuat lintasan berarah relatif utara-selatan atau memotong tubuh bijih yang berarah relatif barattimur. Jarak pengukuran antar titik adalah sekitar $10 \mathrm{~m}$ pada daerah seluas kurang lebih $8 \mathrm{~km}^{2}$. Hasil pengukuran kadar uranium dan thorium selanjutnya dihitung secara statistik sederhana untuk mengetahui sebaran anomali kadar uranium dan thorium.

d. Pengambilan sampel bijih diambil dengan dua cara, yaitu pada bijih yang masih segar untuk analisis mineragrafi dan pada bijih yang telah lapuk untuk analisis butir, lokasi pengambilan sampel terdapat pada (Gambar 3). Analisis mineragrafi bertujuan untuk mengetahui komposisi mineral bijih. Sampel bijih segar selanjutnya dibuat sayatan poles dan diamati dengan mikroskop polarisasi sinar pantul. Sampel bijih lapuk diambil pada lokasilokasi parit uji (Gambar 3) dengan cara channel sampling selanjutnya didulang secara tradisional untuk mendapatkan sampel konsentrat mineral berat.

e. Analisis butir sampel konsentrat mineral berat dilaksanakan dengan cara memasukkan sampel dari lapangan ke dalam cairan tetra bromoetan untuk mendapatkan mineral dengan berat jenis lebih dari $2,7 \mathrm{gr} / \mathrm{cm}^{3}$. Mineral yang mengendap dalam cairan tetra bromoetan selanjutnya dikeringkan. Sampel konsentrat mineral berat selanjutnya diamati di bawah mikroskop untuk mengetahui jenis mineral yang terkandung dalam konsentrat mineral berat. Mineral yang mengambang dalam cairan tetra bromoetan selanjutnya dibuang karena merupakan mineral ringan. 


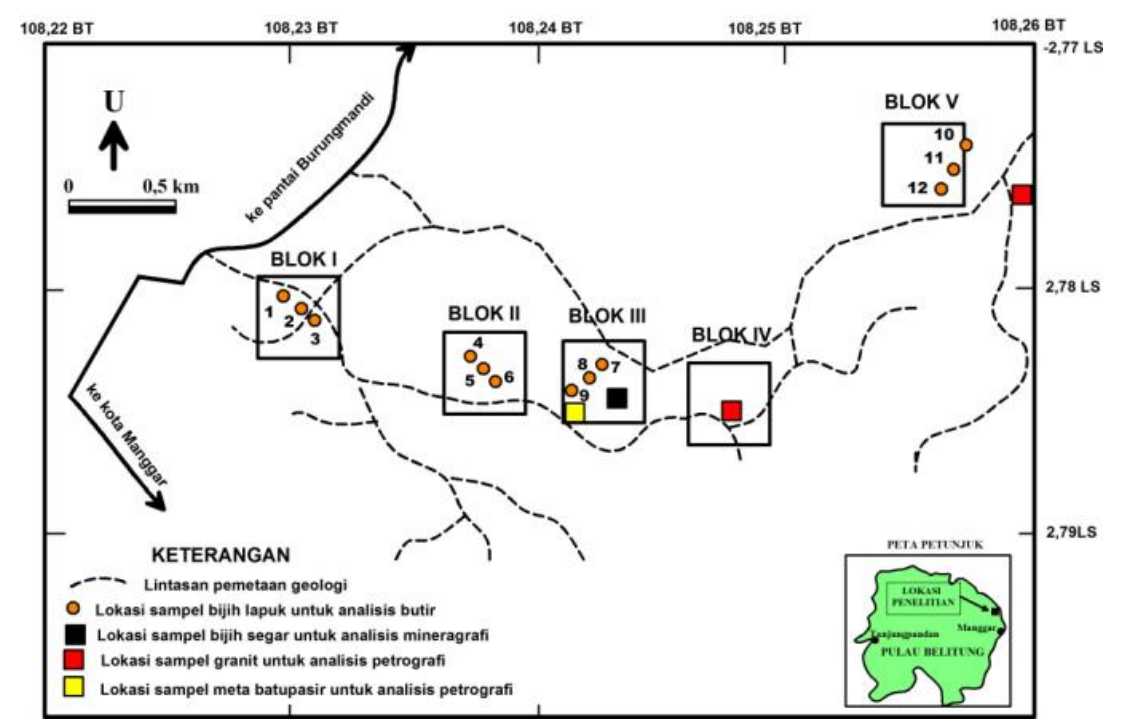

Gambar 3. Peta lintasan pemetaan geologi, lokasi pengambilan contoh batuan dan bijih.

\section{HASIL}

\section{Geologi Regional}

Secara regional geologi daerah Batubesi tersusun oleh Formasi Kelapakampit dan diorit kuarsa Batubesi. Formasi Kelapakampit tersusun oleh batuan sedimen flysh yang terlipat lemah hingga sedang terdiri dari batupasir malih berselingan dengan batusabak, batulumpur, serpih, batulanau tufaan, dan rijang. Formasi ini terendapkan dalam lingkungan laut dan berumur Permo Karbon. Diorit kuarsa Batubesi berwarna hijau-kelabu muda, holokristalin berbutir sedang, hipidiomorfik granular. Komposisi mineral terdiri atas kuarsa, plagioklas, $\mathrm{K}$. feldspar, biotit, hornblenda, klorit, dan oksida besi. Batuan ini berumur 116-160 juta tahun atau Kapur [2].

\section{Geologi Daerah Penelitian}

Hasil penelitian lapangan, laboratorium, dan studio menjumpai kondisi geologi daerah penelitian dicirikan oleh morfologi bergelombang lemah dengan kemiringan lereng $0^{\circ}-5^{\circ}$ yang dibentuk oleh bekas kegiatan penambangan bijih besi secara terbuka. Litologi yang menyusun daerah penelitian adalah satuan metabatupasir dan satuan terobosan granit (Gambar 4).

Secara mikroskopis, satuan batuan metabatupasir memiliki tekstur masif, sortasi sedang-baik, kemas tertutup, bentuk butir membundar tanggung-menyudut tanggung, diameter butir $0,03-0,7 \mathrm{~mm}$, tersusun atas kuarsa $87 \%$, orthoklas $2 \%$, mineral opak $10,5 \%$, dan semen silika 0,5\% (Gambar 5) Secara regional satuan batuan metabatupasir dapat disebandingkan dengan Formasi Kelapakampit yang berumur Permo Karbon. 


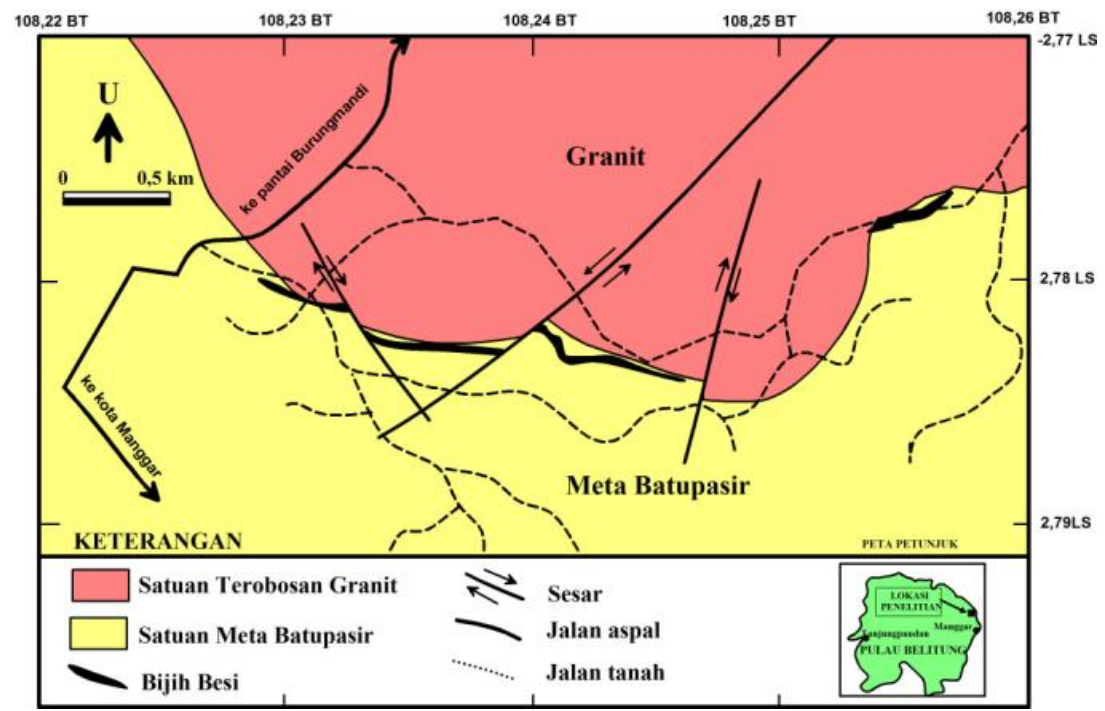

Gambar 4. Peta geologi dan sebaran bijih besi daerah Batubesi, Kecamatan Damar, Kabupaten Belitung Timur.

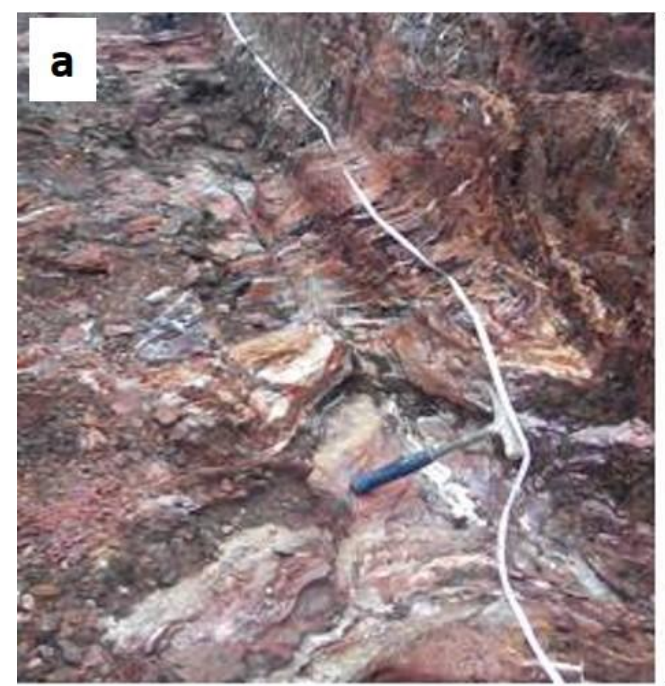

Gambar 5. a. Singkapan Metabatupasir, b. Kenampakan petrografi metabatupasir

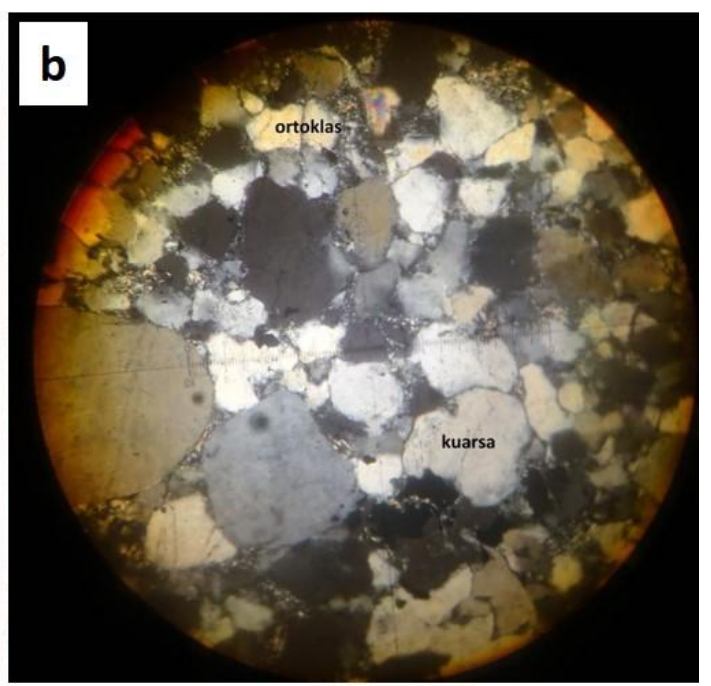

Satuan granit biotit di daerah penelitian terdiri dari granit biotit dan granit hornblenda. Granit biotit secara mikroskopis dicirikan oleh struktur masif, hampir equigranular, bentuk kristal subhedral-euhedral, diameter kristal 0,3-1 mm dan tersusun atas kuarsa $28 \%$, krstal ortoklas $48 \%$, plagioklas $15 \%$, biotit $8,8 \%$, apatit $0,1 \%$, monasit $0,1 \%$, dan kasiterit $0,05 \%$ (Gambar 6). Plagioklas umumnya subhedral berupa oligoklas (An28). Sebagian plagioklas telah terubah menjadi mineral lempung. Alkali felspar terdiri dari ortoklas dan mikroklin, sebagian alkali feldspar telah terubah menjadi mineral lempung dan serisit. Beberapa kuarsa dan ortoklas tumbuh bersama membentuk tekstur grafik dan terdapat kuarsa sebagai fenokris berukuran 4-12 mm. Biotit sebagian telah terubah menjadi klorit dan oksida besi.

Granit hornblenda, abu-abu kehijauankecoklatan, holokristalin, alotriomorfik granular dengan ukuran mineral 1-3 mm. Komposisi mineral penyusun adalah plagioklas $16 \%$, alkali felspar $35 \%$, kuarsa $25 \%$, hornblenda $16 \%$, biotit $6 \%$, apatit $0,2 \%$, zirkon $0,1 \%$, monasit $0,3 \%$, sfen $0,1 \%$, dan mineral opak 1,3\% (Gambar 7). Beberapa plagioklas berstruktur zonal dan mempunyai 
kembaran albit dan karlsbad tetapi tidak dapat digunakan untuk menentukan jenis plagioklas. Sebagian plagioklas telah terubah menjadi serisit dan mineral lempung. Alkali felspar terdiri dari ortoklas dan mikroklin, sebagian alkali feldspar telah terubah menjadi mineral lempung dan serisit. Sebagian biotit telah terubah menjadi klorit. Beberapa monasit memperlihatkan pleokroik halo pada hornblenda, biotit, dan klorit.

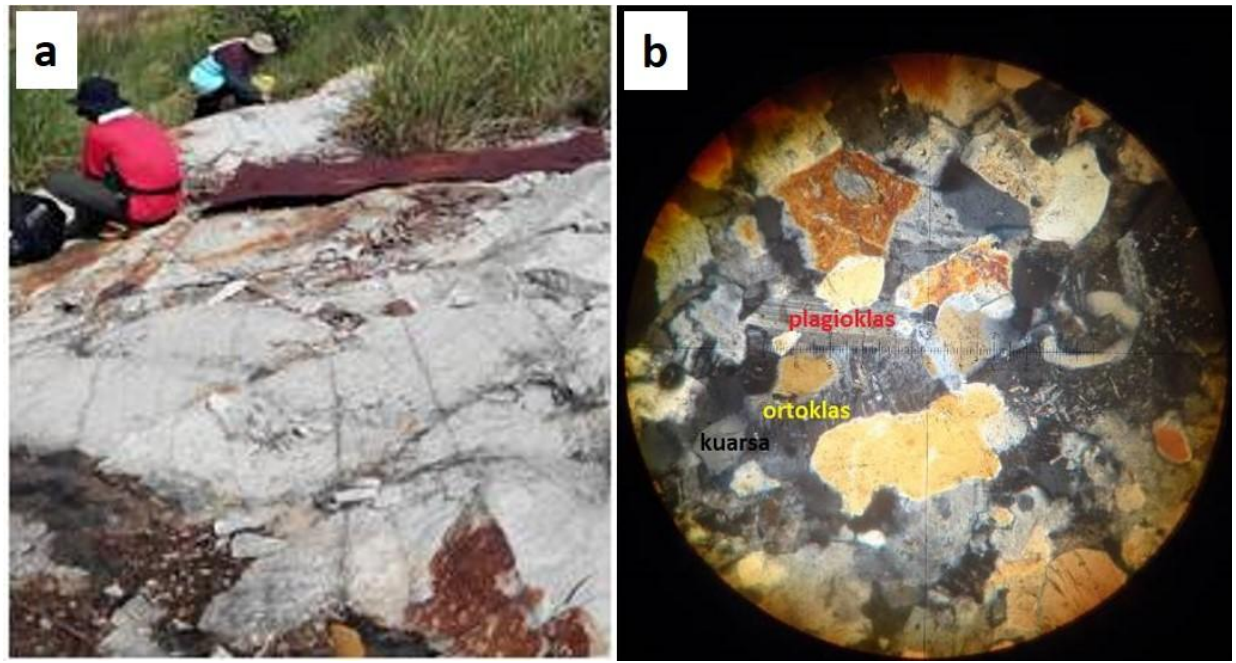

Gambar 6. a. Singkapan Granit Biotit, b.Kenampakan mikroskopis granit biotit.

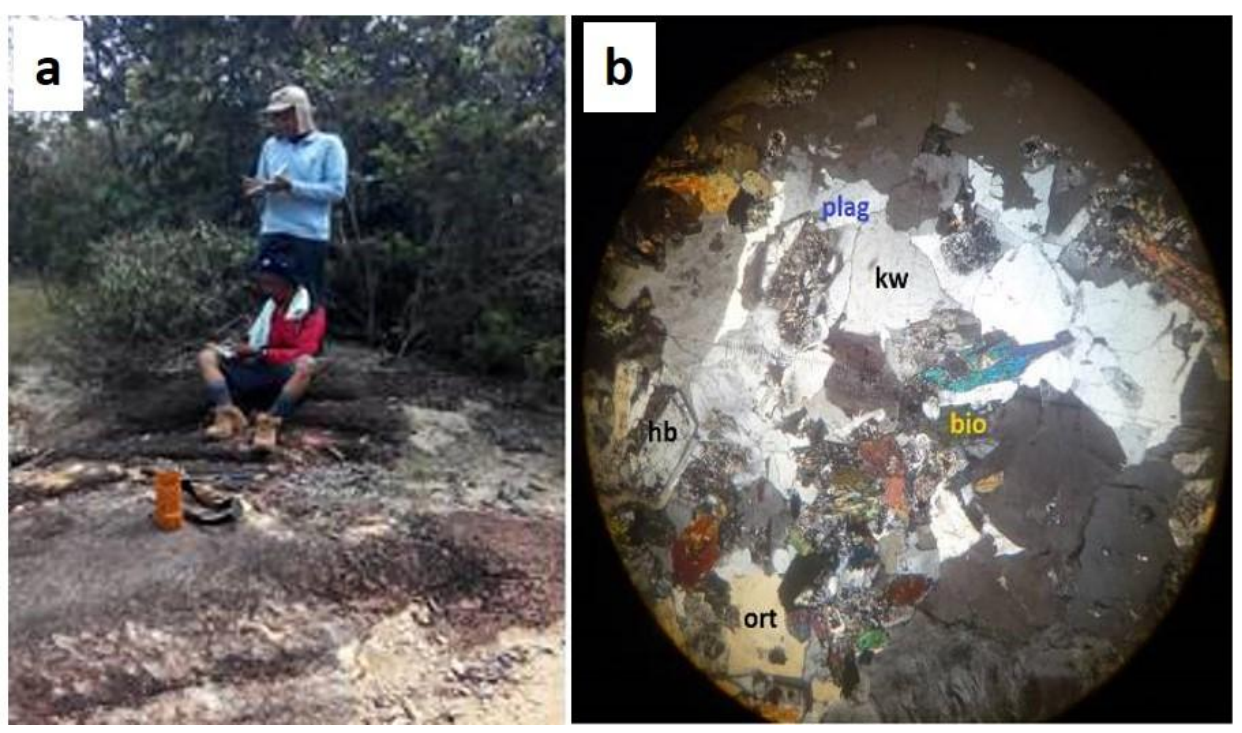

Gambar 7. a. Singkapan granit hornblenda, b. Kenampakkan mikroskopis granit hornblenda.

Struktur geologi yang berkembang adalah sesar dan kekar. Sesar terdiri atas sesar mendatar sinistral berarah baratdayatimurlaut dan sesar mendatar dekstral berarah baratlaut-tenggara. Sedangkan kekar memiliki arah barat-timur, barat lauttenggara, dan timur laut-barat daya. Kekarkekar tersebut terisi bijih besi (Gambar 4).

\section{Cebakan Bijih}

Untuk mengidentifikasi cebakan bijih yang terdapat dalam batuan di daerah penelitian metoda pendekatan yang digunakan adalah analisis mineragrafi untuk sampel bijih yang masih segar dan analisis butir untuk sampel bijih yang telah lapuk. Komposisi mineral hasil analisis mineragrafi dari sampel bijih yang diambil di sekitar 
kontak antara satuan batuan malihan dengan terobosan granit adalah oksida besi $40 \%$, gutit $22,50 \%$, sphalerit 7,85\%, kasiterit 2,10\%, ilmenit 0,25\%, dan mineral lain 27,30\%.

Sementara itu komposisi mineral hasil analisis butir konsentrat dulang yang berasal dari sampel bijih lapuk yang diambil pada beberapa parit uji adalah magnetit, hematit, ilmenit, monasit, zirkon, kasiterit, rutil, hornblenda, dan kuarsa (Tabel 1).

Tabel 1. Hasil analisis butir konsentrat dulang sampel bijih lapuk yang berasal dari parit uji.

\begin{tabular}{cccccccccc}
\hline $\begin{array}{c}\text { No. } \\
\text { Sampel }\end{array}$ & $\begin{array}{c}\text { Magnetit } \\
(\%)\end{array}$ & $\begin{array}{c}\text { Hematit } \\
(\%)\end{array}$ & $\begin{array}{c}\text { Ilmenit } \\
(\%)\end{array}$ & $\begin{array}{c}\text { Monasit } \\
(\%)\end{array}$ & $\begin{array}{c}\text { Zirkon } \\
(\%)\end{array}$ & $\begin{array}{c}\text { Kasiterit } \\
(\%)\end{array}$ & $\begin{array}{c}\text { Rutil } \\
(\%)\end{array}$ & $\begin{array}{c}\text { Hornblenda } \\
(\%)\end{array}$ & $\begin{array}{c}\text { Kuarsa } \\
(\%)\end{array}$ \\
\hline 1 & 83,7 & 12 & 2,48 & 0,51 & 0,88 & 0,14 & 0,08 & 0 & 0,21 \\
2 & 84,2 & 10,66 & 3,35 & 0,58 & 0,22 & 0,3 & 0,05 & 0 & 0,82 \\
3 & 84,93 & 11,5 & 2,05 & 0,21 & 0,04 & 0,28 & 0,02 & 0 & 0,97 \\
4 & 83,98 & 10,87 & 2,9 & 0,6 & 0,3 & 0,46 & 0 & 0 & 0,89 \\
5 & 85,3 & 11,12 & 1,96 & 0,36 & 0,28 & 0,24 & 0 & 0 & 0,74 \\
6 & 84,11 & 10,58 & 3,03 & 0,62 & 0,32 & 0,47 & 0 & 0 & 0,87 \\
7 & 85,87 & 10,73 & 1,22 & 0,23 & 0,25 & 0,1 & 0,15 & 0,2 & 1,25 \\
8 & 69,98 & 12,18 & 3 & 3,16 & 0,45 & 2,84 & 0,55 & 1,42 & 6,42 \\
9 & 93,47 & 5,16 & 1,16 & 0 & 0 & 0 & 0 & 0 & 0,21 \\
10 & 83,5 & 6,34 & 7,56 & 0,54 & 0,26 & 1,01 & 0,13 & 0,15 & 0,51 \\
11 & 82,66 & 2,82 & 1,6 & 1,53 & 0,66 & 9,84 & 0,32 & 0,47 & 0,1 \\
12 & 79,28 & 18,2 & 2,32 & 0 & 0 & 0 & 0 & 0,1 & 0,1 \\
\hline
\end{tabular}

\section{Sebaran Uranium dan Thorium}

Jumlah titik pengukuran kadar uranium yang dilakukan menggunakan alat spektrometer sinar gamma RS 125 pada daerah penelitian adalah 3.600 titik (Gambar 8). Kadar uranium hasil pengukuran berkisar antara 0 sampai dengan 28,5 ppm eU. Hasil perhitungan secara statistik mendapatkan kadar rata-rata 5,25 ppm, simpangan baku 3,47 ppm. Anomali diasumsikan kadar ratarata ditambah dua kali simpangan baku. Anomali kadar uranium daerah penelitian adalah 5,25 ppm $+6,94 \mathrm{ppm}=12,19 \mathrm{ppm}$. Daerah yang dianggap menarik, yaitu daerah yang mempunyai kadar 12,19 sampai dengan 28,5 ppm eU yang terdapat pada daerah kontak antara satuan batuan malihan dan terobosan granit di blok II, III, dan IV (Gambar 9).
Jumlah titik hasil pengukuran kadar thorium yang dilakukan menggunakan alat spektrometer sinar gamma RS 125 pada daerah penelitian adalah 3.783 titik. Kadar thorium hasil pengukuran berkisar antara 1,4 sampai dengan 179 ppm eTh. Hasil perhitungan secara statistik mendapatkan kadar rata-rata 31,31 ppm, simpangan baku 17,16 ppm. Anomali diasumsikan kadar ratarata ditambah dua kali simpangan baku. Anomali kadar thorium daerah penelitian adalah 31,31 ppm $+34,32 \mathrm{ppm}=65,63 \mathrm{ppm}$. Daerah yang dianggap menarik, yaitu daerah yang mempunyai kadar 65,63 sampai dengan 179 ppm eTh yang terdapat pada daerah kontak antara satuan batuan malihan dan terobosan granit di blok I, II, III, dan IV (Gambar 10). 


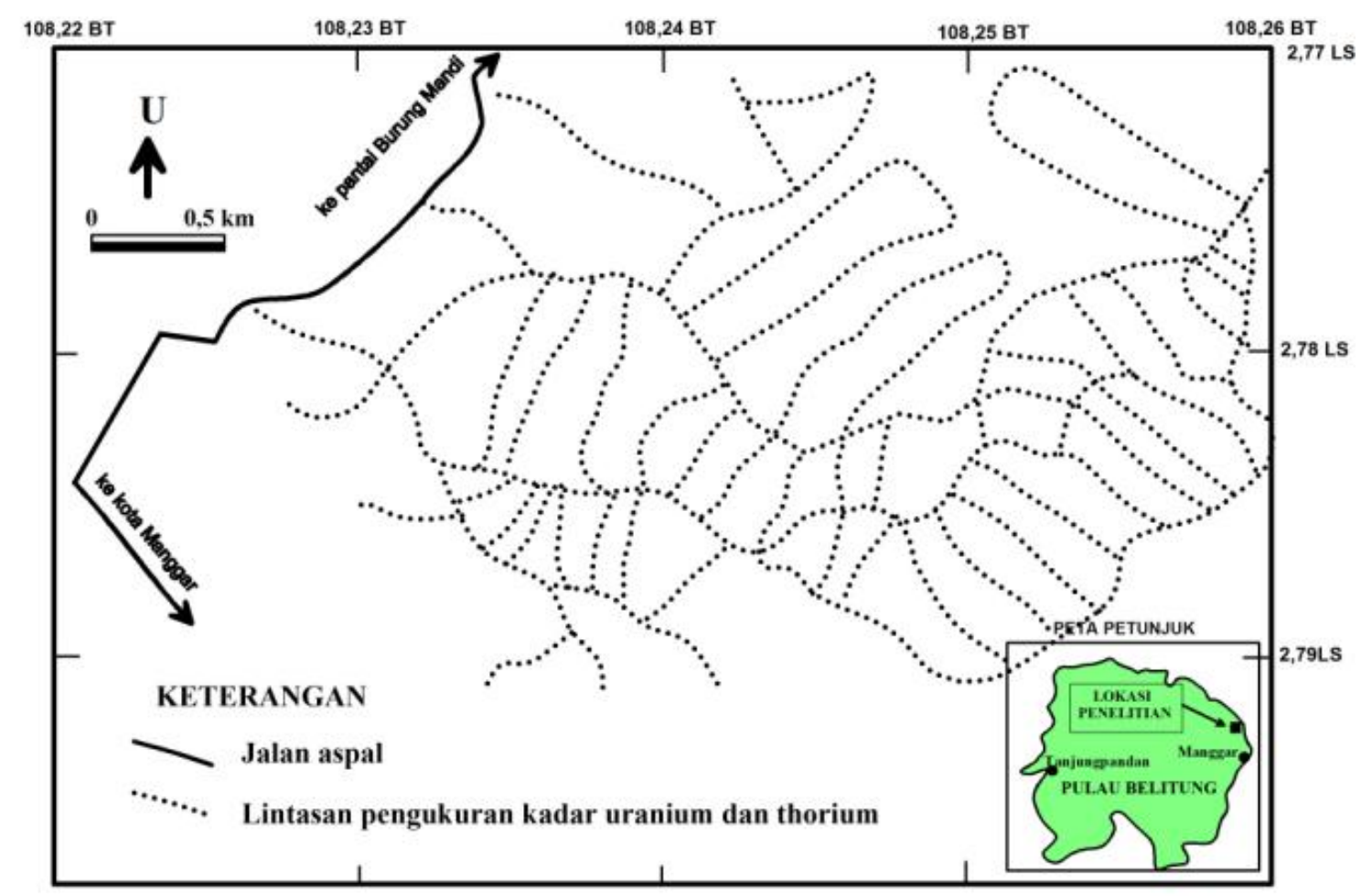

Gambar 8. Peta lintasan pengukuran kadar uranium dan thorium menggunakan RS-125.

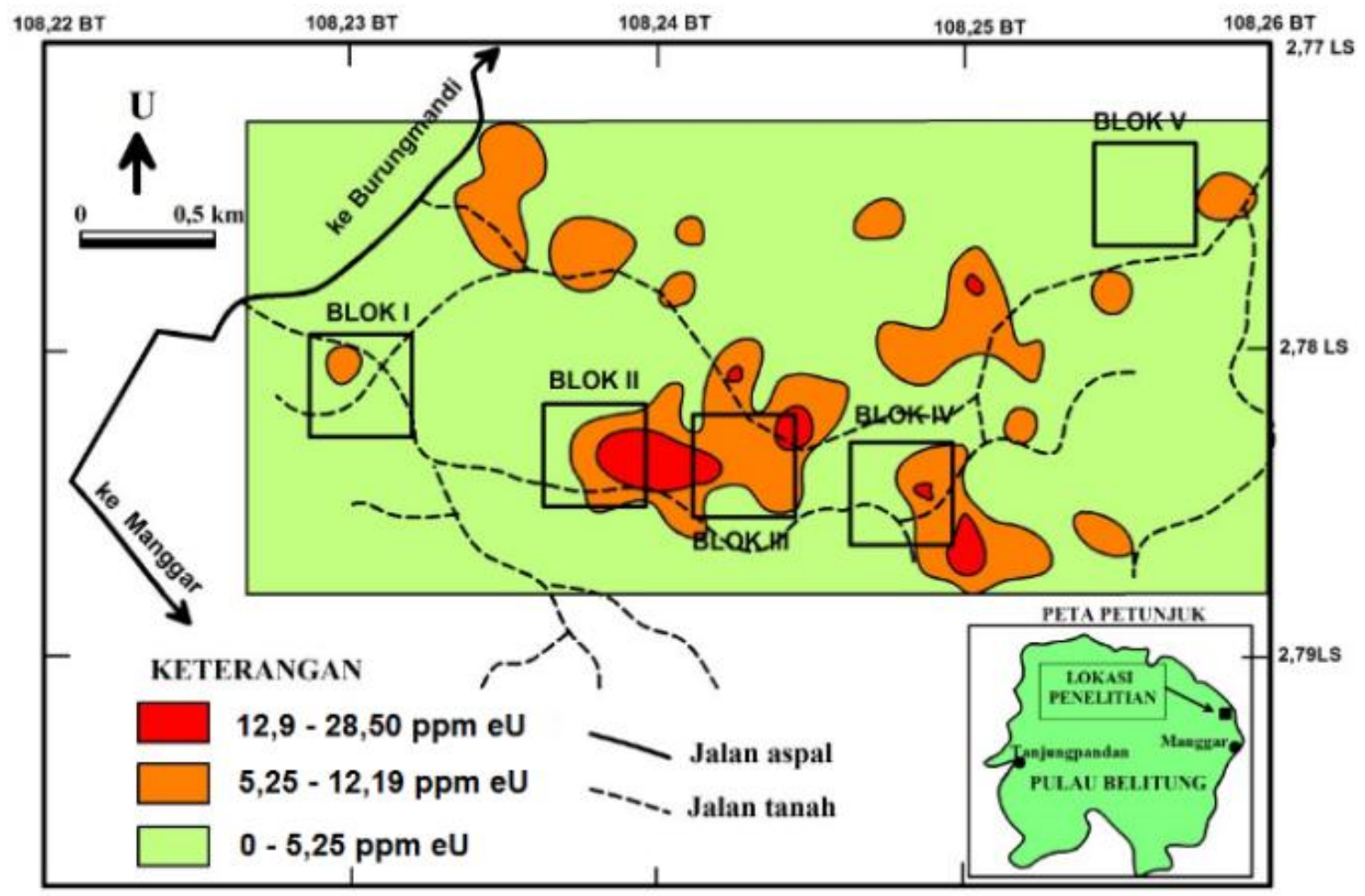

Gambar 9. Peta sebaran kadar uranium daerah Batubesi Kecamatan Damar, Kabupaten Belitung Timur. 


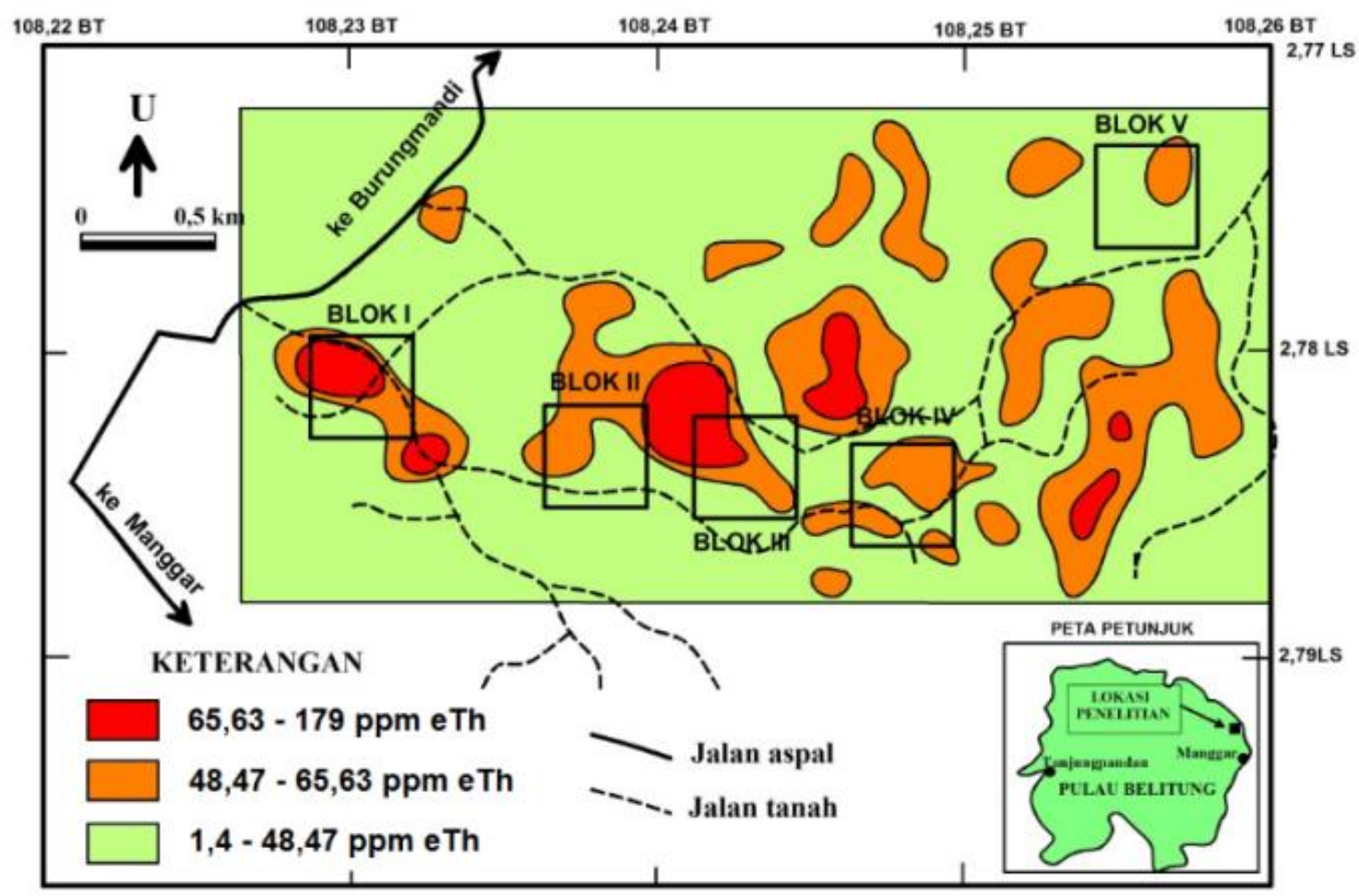

Gambar 10. Peta sebaran kadar thorium daerah Batubesi Kecamatan Damar, Kabupaten Belitung Timur.

\section{PEMBAHASAN}

Secara regional geologi di daerah penelitian tersusun oleh diorit kuarsa Batubesi yang berumur Kapur dan Formasi Kelapakampit yang berumur Permo Karbon. Formasi Kelapakampit tersusun atas batuan sedimen flysch yang terlipat lemah hingga sedang dan terdiri dari batupasir malih berselingan dengan batusabak, batulanau tufan, dan rijang. Hasil pemetaan geologi menunjukkan bahwa daerah penelitian tersusun oleh satuan granit dan satuan metabatupasir. Satuan granit secara regional dapat disebandingkan dengan diorit kuarsa Batubesi sedangkan satuan metabatupasir diperkirakan merupakan bagian dari Formasi Kelapakampit. Satuan granit tersusun oleh granit biotit dan granit hornblenda. Granit hornblenda adalah salah satu penciri granitoid tipe I sehingga kandungan timah, monasit, dan zirkon tidak banyak bila dibandingkan dengan granit tipe $S$ [3][4]. Hasil analisis petrografi pada granit, baik granit biotit maupun granit hornblenda memperlihatkan bahwa pada sebagian biotit telah terubah menjadi klorit. Proses kloritisasi dari biotit menjadi klorit umumnya disertai pembentukan mineralisasi yang kaya rutil dan kasiterit seperti pada granit di jalur bagian barat Nanling, China Selatan [5] sehingga keterdapatan kasiterit di daerah penelitian diperkirakan berhubungan dengan proses kloritisasi biotit.

Hasil analisis mineragrafi dari bijih yang diambil di sekitar kontak antara metabatupasir dan granit menunjukkan komposisi mineral sebagai berikut: oksida besi $40 \%$, gutit $22,50 \%$, sphalerit $7,85 \%$, kasiterit $2,10 \%$, ilmenit $0,25 \%$, dan mineral pembentuk batuan $27,30 \%$. Dengan data hasil analisis mineragrafi tersebut maka cebakan bijih di daerah penelitian adalah cebakan bijih besi primer dengan mineral utama adalah oksida besi dan gutit dengan mineral ikutan terdiri dari spalerit, kasiterit, dan ilmenit. Secara geologi dan tektonik daerah Batubesi 
terletak pada jalur timur dari granit jalur Timah Asia Tenggara, sehingga kandungan timah dan mineral ikutan radioaktifnya sedikit. Jika dibandingkan dengan hasil analisis mineragrafi pada cebakan bijih primer pada granit di daerah Gadung, Bangka Selatan yang merupakan jalur utama dari granit jalur timah Asia Tenggara maka yang terbentuk adalah cebakan bijih timah primer dengan komposisi mineral adalah kasiterit $96,70 \%$, rutil $0,02 \%$, monasit $0,02 \%$, stanit $0,01 \%$, galena $1,25 \%$, dan mineral transparan $2 \%$ [6]. Dari data tersebut maka dapat dinyatakan bahwa di sekitar Bangka Belitung keterdapatan timah dan mineral radioaktif ikutanya di jalur utama lebih prospek dibanding jalur timur. Pengembangan eksplorasi mineral radioaktif untuk cebakan primer sebaiknya diarahkan pada jalur utama dari granit jalur timah Asia Tenggara.

Komposisi mineral hasil analisis butir konsentrat dulang yang berasal dari 12 buah sampel bijih yang diambil dari empat parit uji adalah magnetit $69,98-93,47 \%$, hematit 2,82 $-12,18 \%$, ilmenit $1,16-7,56 \%$, monasit 0,21 $-3,16 \%$, zirkon $0,04-0,88 \%$, kasiterit $0,1-$ $9,84 \%$, dan rutil $0,02-0,55 \%$. Dari data tersebut maka diperkirakan cebakan bijih di daerah penelitian adalah cebakan bijih besi primer dengan magnetit sebagai mineral utama dan hematit, ilmenit, monasit, zirkon, kasiterit, dan rutil merupakan mineral ikutan.

Hasil analisis 12 sampel bijih lapuk di daerah Granit Gadung Bangka Selatan adalah kasiterit 1,39-95,02\%, zirkon 0,24-58,2\%, ilmenit $0,26-47,3 \%$, hematit 1,16-42,21\%, monasit 0,33 - 13,76\%, magnetit 0,06 $0,54 \%$, dan rutil $0,36-3,55 \%$. Bila dibandingkan dengan daerah Gadung, Bangka Selatan maka terlihat bahwa cebakan bijih di daerah Batubesi adalah cebakan bijih besi sedangkan di daerah Gadung adalah cebakan bijih timah. Pada kedua cebakan tersebut terdapat mineral ikutan radioaktif yang terdiri atas mineral monasit dan zirkon.

Cebakan bijih besi di daerah Batubesi diperkirakan mempunyai kemiripan dengan cebakan skarn iron tin polymetallic Huanggang yang terdapat di Cina bagian timurlaut [7] dan cebakan tin polimetalik Dafulou di Cina bagian selatan [8]. Cebakan iron tin polymetallic Huanggang dan Dafulou ditandai dengan kehadiran mineral sphalerit. Hasil analisis mineragrafi dari bijih besi di daerah Batubesi juga ditandai dengan kehadiran mineral sphalerit.

Hasil pengukuran kadar uranium dan thorium memperlihatkan bahwa zona anomali kadar uranium dan thorium terdapat pada zona kontak antara satuan metabatupasir dan granit atau lebih tepatnya zona anomali uranium dan thorium terdapat di sekitar zona bijihbesi. Dengan hasil tersebut maka dapat dinyatakan bahwa pengukuran kadar uranium dan thorium menggunakan alat spektrometer sinar gamma RS-125 dapat membantu mendeliniasi bijih besi yang mengandung mineral radioaktif terutama monasit dan zirkon. Gabungan pemetaan geologi dan pengukuran kadar uranium dan thorium menggunakan spektrometer sinar gamma di daerah Um Naggat, Mesir juga dapat mendeliniasi mineralisasi uranium pada granit [9][10].

Hasil studi awal tentang potensi bahan galian di Belitung Timur yang dilakukan oleh peneliti terdahulu menyimpulkan bahwa daerah Batubesi merupakan daerah yang potensial terdapat cebakan bijih besi [11]. Mengacu data hasil penelitian ini dan data dari peneliti terdahulu maka daerah Batubesi adalah daerah potensial bijih besi dengan mineral ikutan timah, monasit, dan zirkon. 


\section{KESIMPULAN}

Litologi daerah penelitian tersusun atas satuan metabatupasir dan satuan terobosan granit. Satuan metabatupasir terdiri dari metabatupasir yang secara regional merupakan bagian dari Formasi Kelapakampit berumur Permo Karbon. Satuan granit terdiri dari granit biotit dan granit hornblenda yang secara regional dapat disebandingkan dengan diorit kuarsa Batubesi berumur Kapur. Struktur geologi yang berkembang adalah sesar mendatar sinistral berarah barat daya-timur laut dan tenggarabarat laut.

Cebakan bijih di daerah penelitian adalah cebakan bijih besi primer tipe skarn iron tin polymetallic dengan mineral utama adalah magnetit dan mineral ikutan radioaktif berupa monasit dan zirkon serta mineral ikutan lainya adalah hematit, ilmenit, kasiterit, dan rutil.

\section{UCAPAN TERIMA KASIH}

Pada kesempatan yang baik ini penulis mengucapkan terima kasih yang sebesarbesarnya kepada PT. Timah yang telah mengijinkan penulis untuk melakukan penelitian dan memanfaatkan parit uji yang ada di IUP PT. Timah daerah Batubesi, Belitung Timur. Terima kasih juga kami ucapkan kepada Kepala Pusat Teknologi Bahan Galian Nuklir yang telah memberikan kesempatan kepada penulis untuk melakukan penelitian ini. Penulis juga mengucapakan terima kasih kepada rekan-rekan laboratorium, antara lain Tukijo, Widodo, dan Manto Widodo yang telah membantu di dalam analisis petrografi dan mineragrafi.

\section{DAFTAR PUSTAKA}

[1] M. O. Schwartz, S. S. Rajah, A. K. Askury, P. Putthapiban, and S. Djaswadi, "The Southeast Asian Tin Belt," Earth-Science Reviews, vol. 38, pp. 95-293, 1995.

[2] Baharuddin dan Sidarto, "Peta Geologi Lembar Belitung, Sumatera Skala 1 : 250.000," Pusat Penelitian dan Pengembangan Geologi, Bandung, 1995.

[3] S. Wai-Pan Ng, S. Chung, L. J. Robb, M. P. Searle, A. A. Ghani, M. J. Whitehouse, G. J. H. Oliver, M. Sone, N. J. Gardiner, and M. H. Roselee, "Petrogenesis of Malaysian Granitoids in the Southeast Asian Tin Belt: Part 1. Geochemical and $\mathrm{Sr}-\mathrm{Nd}$ Isotopic Characteristics," Geological Society of America Bulletin, published online on 3 April 2015.

[4] C. Wang, J. Deng, E. J. M. Carranza, and M. Santish, "Tin Metallogenesis Associated with Granitoid in the Southwestern Sajinag Tethyan Domain: Nature, Deposit Type and Tectonic Setting," Gondwana Research, vol. 26, pp.576593, 2014.

[5] R. C. Wang, L. Xie, J. Chen, A. Yu, L. Wang, I. $\mathrm{Lu}$, and J. Zhu, "Tin-Carrier Minerals in Metaluminous Granites of the Western Nanling Range (southern China): Constraints on Processes of Tin Mineralization in Oxidized Granites," Journal of Asian Earth Sciences, vol. 74, pp. 361-372, 2013.

[6] Ngadenin, "Sebaran Monasit pada Granit dan Aluvial di Bangka Selatan," Jurnal Pengembangan Energi Nuklir, vol. 13, no. 2, pp. 102-110, 2011.

[7] W. Mei, X. Lu, X. Cao, Z. Liu, Y. Zhao, Z. Ai, R. Tang, and M. M. Abfaua, "Ore Genesis and Hydrothermal Evolution of the Huanggang Skarn Iron-Tin Polymetallic Deposit, Southern Great Xing'an Range: Evidence from Fluid Inclusions and Isotope Analyses," Ore Geology Reviews, vol. 64, pp. 239-252, 2015.

[8] C. Yongsheng, "Geochemical Characteristics of the Fluid Inclusion of the Dafulou Deposits in Guangxi, China," Procedia Environmental Sciences, vol. 12, pp. 366-371, 2012.

[9] I. Gaafar, "Integration of Geophysical and Geological Data for Delimitation of Mineralized Zones in Um Naggat Area, Central Eastern Desert, Egypt," NRIAG Journal of Astronomy and Geophysics, vol. 4, pp. 86-99, 2015. 
[10] A. A. Elkhadragy, A. A. Ismail, M. M. Eltarras, and A. A. Azzazy, "Utilization of Airborne Gamma Ray Spectrometric Data for Radioactive Mineral Exploration of G.Abu Had-G.Umm Qaraf Area, South Eastern Desert, Egypt,“ NRIAG Journal of Astronomy and Geophysics, 2016.
[11] N. Natasia, M. N. Barkah, D. H. Saputra, dan M. K. Alfadli, "Studi Awal Potensi Bahan Galian pada Daerah Kabupaten Belitung Timur, Indonesia," Bulletin of Scientific Contribution, vol. 14, no. 2, pp. 153-162, 2016. 